\title{
Knowledge and Attitudes of Pregnant Women regarding Urinary Tract Infection
}

\section{Sania Elsayed Abd Elfatah ${ }^{1}$, Soad Abd Elsalam Ramadan², Amina Saad Gonied ${ }^{3}$, and Fatma Kamal Ali ${ }^{4}$}

(1)B.SC.in Nursing 2007- Faculty of Nursing-Benha University, Supervisor in Benha fever hospital. (2)Professor of Obstetrics \&Gynecological Health Nursing Faculty of Nursing-Benha University (3 )Professor of Obstetrics \& Woman's health Nursing, Faculty of Nursing- Zagazig University (4)Lecturer of Obstetrics \& Woman's health Nursing, Faculty of Nursing-Benha University

\begin{abstract}
Background: Urinary tract infection is one of the most common bacterial infections during pregnancy. The aim of this study was to assess knowledge and attitudes of pregnant women regarding urinary tract infection. Research design: A descriptive research design was utilized to conduct this study. Setting: The study was conducted at obstetrics and gynecological outpatient clinic affiliated to Benha University Hospital. Sample: A convenient sample used in the study, it included 220 pregnant women. Tools: Three tools were used: A structured interviewing questionnaire, Maternal Knowledge Questionnaire and Likert scale of women attitudes toward urinary tract infection. Results: Less than three quarters of the studied women $(70.5 \%)$ had average total knowledge about urinary tract infection. majority the studied women $(84.1 \%)$ had positive attitude about urinary tract infection. There were a highly statistically significance relation between the total knowledge score of the studied women and educational level, occupation, monthly income, residence and family type. Also, there were highly statistically significance relation between the total attitude score of the studied women and income and family type. Conclusion: There was a highly statistically significance relation between the total knowledge score of the studied women and total attitude score. Recommendation: An intensive awareness program should be developed and implemented for pregnant women to avoid urinary tract infection.
\end{abstract}

Key words; Pregnant Women, Urinary Tract, Infection.

\section{Introduction}

Pregnancy is physiological .psychological and biological stressful even for healthy women Problems like hyperemesis gravidarum, bleeding, anemia, hypertensive disorder, diabetes mellitus, infection like rubella, toxo plasmosis, group B streptococcus, urinary tract infection will complicate the pregnancy. During pregnancy, there is anatomical changes in the urinary system, it is due to the increased progesterone level as it relaxes the wall of the ureter and its allows kinking and dilatation and also by the pressure from the enlarged uterus .So urinary tract infection is the most common medical complication of pregnancy after anemia (Sobin and Robin, 2018)

Urinary tract infection(UTI) is an infection in the urinary tract caused by the presence of pathogenic bacterial organisms within the genitourinary tract which may be diagnosed from the laboratory investigation of the urine and symptoms there are many varies clinical manifestation, but the symptoms may include lower abdominal pain , foul smelling 


\section{Knowledge and Attitudes of Pregnant Women regarding Urinary Tract Infection}

urine and unknown origin fever .Escherichia coli is the commonest cause of UTI have been found in the pregnant women about (80-90\%) then klebsiella, Enteriobacter (Gondwe and Alfred ,2020) .The other symptoms include ; incomplete voiding ,frequent micturition and dribbling of urine (Hend Abdullah, 2019)

Urinary tract infection is the second most common bacterial infection and the most common bacterial disease in the pregnant women .UT usually begin in at the 6 week and during 22to 24 week. UTI are calcified into, Asymptomatic bacteria occur in $4 \%$ to $8 \%$ of all pregnancies, pyelonephritis occur in $1 \%$ to $2 \%$ of pregnancies and cystitis that $1 \%$ of pregnant women have acute cystitis. the urinary tract infection may lead to several complication in the pregnant women such as low birth weight baby , abortion ,prematurity ,preeclampsia ,preterm labor, stillbirth , chronic pyelonephritis and rarely kidney failure so if the UTI if not treated early the mortality rate of the mothers and baby will increased (Sobin and Robin , 2018).

\section{Significance of the study}

Urinary tract infection (UTI) it is the most serious health problem affecting millions of people each year and it is one of the most common medical complications of pregnancy. The incidence of UTI during pregnancy increased because physiological and the anatomical changes that can occur in the genitourinary tract during pregnancy. more ever , women develop ureteral dilatation ,decreased ureteral tone, increased bladder tone, ,resulting in increased of utero vesicle reflux and urinary stasis .so ,up to $70 \%$ of pregnant women develop glycosuria, that encourage bacterial growth in the urine (Hend Abdullah , 2019)
Asymptomatic bacteria occur in $4 \%$ to $8 \%$ of all pregnancies. $1 \%$ of pregnant women have acute cystitis. Pyelonephritis occurs in 1\% to $2 \%$ of pregnancies. Urinary tract infection lead to complication such as prematurity , abortion, still birth, low birth weight baby , preterm labour ,chronic pyelonephritis, preeclampsia and rarely kidney failure. So if the UTI is not treated early, it will harm the baby (Sobin and Robin , 2018).

The prevalence of urinary tract infection In Egypt, about 29\% in Ismailia city, 30.29\%in Suez governorate, and reached to $22 \%$ to $35 \%$ in Zagazige (Mirvat and Salmia, 2018).

UTI is a common problem in pregnancy globally around 8.3 million per year of pregnant women reported the cases of urinary tract infection which is due to increase in weight and size of the uterus that directly affected on the normal mechanism of the bladder (Hend Abdullah , 2019).

\section{Aim of the study}

This study aimed to assess knowledge and attitudes among pregnant women regarding urinary tract infection

\section{Study questions}

1 -What is the level of pregnant women's knowledge regarding urinary tract infection?

2- What is the response of pregnant women's attitudes regarding urinary tract infection?

\section{Subjects and method}

The current study was conducted to assess knowledge and attitudes of pregnant women regarding urinary tract infection that can be achieved through; assess the level of pregnant women's knowledge regarding urinary tract 
infection and assess the response of pregnant women's attitudes regarding urinary tract infection.

\section{Study design:}

A descriptive design was utilized to conduct this study.

\section{Study Setting:}

The study was conducted at obstetrics and gynecological outpatient clinic affiliated to Benha University Hospital. This clinic provides health care services of obstetrics and gynecological women, as well as family planning.

\section{Sample:}

\section{Sample type:}

A convenient sample was used in the study.

\section{Sample size:}

The study subjects consisted of (220) pregnant women was available at the time of data collection.

\section{Sample technique:}

The researcher visited the study setting and explained the purpose of the study to pregnant women and this was repeated 3 times for six months from the beginning of July 2019 to the end of December 2019.

\section{Tools of data collection:}

Three tools were used for data collection.

\section{Tool I- A structured interviewing} questionnaire: this tool was constructed by the researchers after reviewing a related literature (Samanta, 2016; Ngxongo, 2018): and consisted of three parts:

Part (1): Personal characteristics of the study pregnant women such as (age, educational level, work-monthly income, residence, family type, daily habits).
Part (2): Obstetrics history as (number of pregnancy, number of birth, number of life children, type of labor ...).

Part (3): Medical and surgical history such as :( hypertension, DM, anemia).

Tool II: Maternal Knowledge Questionnaire: It used to assess the pregnant women' knowledge regarding urinary tract infection. It included (7 items) that included (definition of urinary tract infection the causes of urinary tract infection during pregnancy, the high risk group for urinary tract infection during pregnancy-the symptoms accompanying urinary tract infection ,the complication of urinary tract infection, the methods of prevention of urinary tract infection and management of urinary tract infection).

Tool III: Likert scale of women attitudes toward urinary tract infection:

This scale was modified by the researcher to measure the pregnant women's attitude toward urinary tract infection. It was adapted by the researchers after reviewing the related literature (Emiru et al., 2016; Samanta, 2016). The researcher used the simple Arabic language to suit the level of women's understanding. This scale included (18 items) such as (pregnancy increases the risk of urinary tract infection, the presence of infection adversely affects personal life, urinary tract infection causes a number of serious health complications in the mother and the fetus, completely empty the bladder during urination reduces the risk of urinary tract infection, drinking 5-8 glasses of water a day helps reduce the risk of infection, using a public toilet increases the risk of urinary tract infection, ensuring that the toilet is clean reduces the risk of infection ,....etc.,). 


\section{Knowledge and Attitudes of Pregnant Women regarding Urinary Tract Infection}

\section{Field work:}

An official permission was obtained from Director of Benha University Hospital and an oral consent from every pregnant women before the beginning of collecting data was obtained after explanation the purpose of the study to gain their consents and cooperation. The actual field work was carried out from the beginning of July 2019 up to the end of December 2019, the period of collected data was 6 months and the researcher visited the pre-mentioned setting from 9am to $12 \mathrm{pm}$, three days /week average time taken to complete each interview ranged from 30- 45 minutes and average pregnant women' number ranged between $2 \backslash 3$ pregnant woman/day.

- Tool I: A structured interviewing questionnaire was utilized to assess personal characteristics of the studied women.

- Tool II: Maternal knowledge questionnaire was utilized to assess pregnant women's knowledge regarding urinary tract infection.

- Tool III: Modified likert scale used to asses pregnant women's attitude regarding urinary tract infection.

\section{Scoring system:-}

Each item was assigned a score of (2) was given when answer was completely correct answer, a score (1) was given when the answer was incompletely correct and a score (0) was given when the answer was don't know.

The total knowledge score was considered good if the percent was more than $75 \%$, average if the percent score were ranged from $50 \%$ to $75 \%$, while it considered poor if the percent score was less than $50 \%$.

\section{Scoring system:-}

Pregnant women response was measured on three point Likert scale that ranged from disagree (0), not sure (1) and agree (2). These scores were converted into percent score, the pregnant women' attitude was considered positive if score $>75 \%$ and negative if score $<50 \%$.

\section{Validity and reliability:}

The tool validity was done by three panel experts in maternity nursing and obstetrics medicine specialty who reviewed the tools for clarity, relevance; comprehensive, applicability and reliability. The reliability was done by Cranach's Alpha which revealed that the internal consistency of knowledge was 0.81 and the internal consistency of the attitude was 0.76 .

\section{Limitation of the study:-}

Occasionally, the waiting place of the obstetrics and gynecological outpatient clinic was crowded and noisy, which required more time and effort to conduct the study.

\section{Pilot study:}

carried out on $10 \%$ of the total duration of collected data (3 weeks ) to test the clarity and applicability of the study tools and estimate the time required to fill the tools, science no modifications have been done, so the number in the pilot was included in the main sample.

\section{Statistical analysis:}

Computerized data entry and statistical analysis were done using (SPSS) Version 20 Descriptive statistics were first applied (numbers, frequency, percentages, tables, figures, diagrams and standard deviation) then other statistical tests such as chi square.

Statistical significance was considered at: 
P- Value $>0.05$ Not significant (NS).

$\mathrm{P}$ - Value $<0.05$ Significant $(\mathrm{S})$.

P- Value $<0.001$ highly significant (HS).

\section{Results}

Table (1) shows that less than half of the studied women $(49.1 \%)$ were in age group 25 $<35$ years old with the mean age of $27.45 \pm 5.75$ years. less than half of the studied women $(45.9 \%)$ had secondary education. More than half of the studied women $(56.8 \%)$ were house wife. While, most of the studied women $(87.3 \%)$ had enough income and two thirds of the studied women $(66.8 \%)$ were living in rural area. In addition to, more than half of the studied women (53.6\%) had nuclear family.

Table (2) shows distribution of studied women regarding medical history. The result revealed that most of studied women (82.3\%) didn't suffered from diseases and less than half of the studied women who were suffered from diseases $(n=39)(48.7 \%)$ were suffered from hypertension. Also, more than half of the studied women $(58.6 \%)$ had problems in the urinary tract associated with UT I, and more than half of the studied women who were had problems in the urinary tract with the previous pregnancy $(n=129)$ and $(56.6 \%)$ of them had urinary stasis with the previous pregnancy

Figure (1) shows that less than three quarters of the studied women $(70.5 \%)$ had average total knowledge about urinary tract infection.

Figure (2) clears that most of the studied women $(84.1 \%)$ had positive attitude about urinary tract infection.

Table (3) shows that there was a highly statistically significance relation between the total knowledge score of the studied women and their total attitude score.

Table (1): Frequency distribution of studied women regarding demographic characteristics $(n=220)$.

\begin{tabular}{|l|l|l|}
\hline Demographic characteristics & No & $\%$ \\
\hline Age & 74 & 33.6 \\
\hline$<25$ & 108 & 49.1 \\
\hline $25-<35$ & 38 & 17.3 \\
\hline $35+$ & $27.45 \pm 5.75$ \\
\hline Mean \pm SD & 33 & 15.0 \\
\hline Educational level & 101 & 45.9 \\
\hline Illiterate & 39.1 \\
\hline Secondary education & 86 & 43.2 \\
\hline University education & 95 & 56.8 \\
\hline Occupation & 125 & 87.3 \\
\hline Working & 192 & 12.7 \\
\hline House wife & 28 & 66.8 \\
\hline Monthly income & 147 \\
\hline Enough & 73 & 33.2 \\
\hline Not enough & \multicolumn{2}{|l|}{} \\
\hline Residence & 102 & 46.4 \\
\hline Rural & 118 & 53.6 \\
\hline Urban & \multicolumn{2}{|l|}{} \\
\hline Family type &
\end{tabular}


Knowledge and Attitudes of Pregnant Women regarding Urinary Tract Infection

Table (2): Frequency distribution of studied women regarding medical history $(\mathrm{n}=220)$.

\begin{tabular}{|c|c|c|}
\hline Items & No & $\%$ \\
\hline \multicolumn{3}{|l|}{ Suffer from diseases } \\
\hline Yes & 39 & 17.7 \\
\hline No & 181 & 82.3 \\
\hline \multicolumn{3}{|l|}{ Type of disease $(n=39)$} \\
\hline Hypertension & 19 & 48.7 \\
\hline Anemia & 11 & 28.2 \\
\hline Diabetes & 9 & 23.1 \\
\hline \multicolumn{3}{|c|}{ Have any problem in the urinary tract associated with $U$ T I } \\
\hline Yes & 129 & 58.6 \\
\hline No & 91 & 41.4 \\
\hline \multicolumn{3}{|c|}{ If yes what is the types of problems $(n=129)$. } \\
\hline Urinary stones & 12 & 14.7 \\
\hline Urinary stasis & 72 & 56.6 \\
\hline $\begin{array}{l}\text { Inflammation of the } \\
\text { kidney pelvis }\end{array}$ & 45 & 41.9 \\
\hline
\end{tabular}

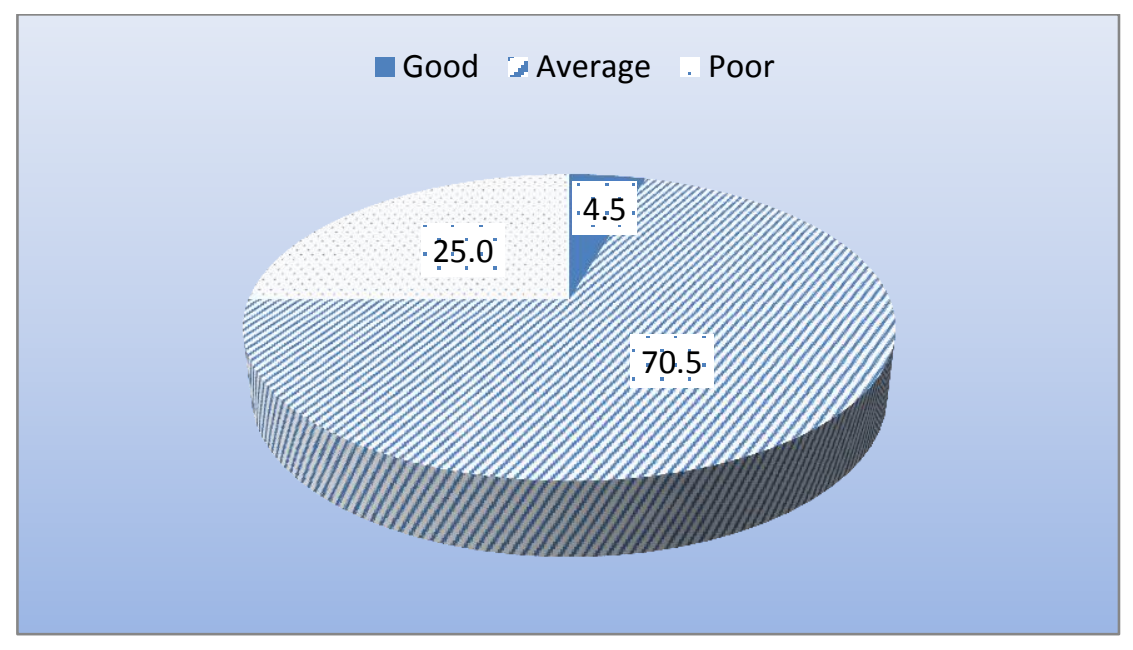

Figure (1): Percentage distribution of studied women regarding total knowledge about urinary tract infection $(n=220)$. 


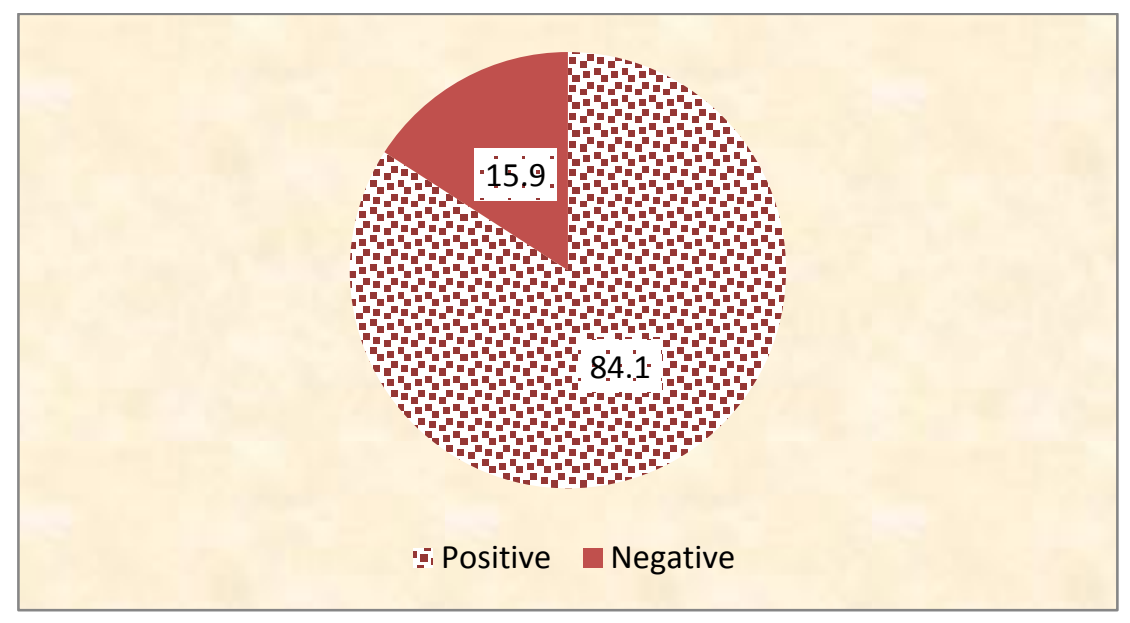

Figure (2): Percentage distribution of studied women regarding their total attitude score about urinary tract infection

Table (3): Correlation between total knowledge and total attitude among studied women $(n=220)$.

\begin{tabular}{|l|l|l|}
\hline \multirow{3}{*}{ Total attitude } & \multicolumn{2}{|c|}{ Total knowledge } \\
\cline { 2 - 3 } & $\mathbf{R}$ & P-value \\
\cline { 2 - 3 } & 0.37 & $0.000^{* *}$ \\
\hline
\end{tabular}

** Highly statistically significance

\section{Discussion}

According to the demographic characteristics of the studied women; the current study showed that less than half of them were in the age group of 25 to less than 35 years old with the mean age of $27.45 \pm 5.75$ years. This result disagreed with Barros (2015), who conducted a study about urinary tract infection during gestation and its correlation with low back pain versus nursing interventions in Brazil, and found that more than half of the pregnant women were aged between 20 to less than 29 years. This might because this is the most appropriate age for marriage and might be due to the difference in the time of conducting the study.

Regarding the educational level of the studied women; the present study revealed that less than half of them had secondary education. This finding was in agreement with El Sayed (2019), who performed a study about pregnant women perception regarding urinary tract infection, and reported that more than half of the studied women had secondary education. This might be because most of the rural families prefer to married their girls than to complete their education.

Concerning the occupation of the studied women, the finding of the present study displayed that more than half of them were housewives (table, 1). This result supported with Safan \& Mohsen (2016), who performed study about knowledge, attitude, practices, and health beliefs of pregnant women about urinary tract infection and its associated risk factors: A local Filipino community experience, and stated 


\section{$\underline{\text { Knowledge and Attitudes of Pregnant Women regarding Urinary Tract Infection }}$}

that the majority of the studied women were housewives.

As regards the studied women monthly income, residence, and family type; findings of the present study displayed that most of the studied women had enough monthly income, more than two thirds of them were living in rural area, and more than half of them had nuclear family. These results supported with Adhikari \& Dhakal (2015), who performed a study about knowledge on urinary tract infection among Primi-gravida women, and stated that more than one quarter of the studied women had enough monthly income, less than three quarters of them were living in rural area, and the majority of them had nuclear family.

As regards the studied women history of urinary tract infection during the current pregnancy; the result of the present study showed that more than half of studied women get urinary tract infection in the $2^{\text {nd }}$ trimester. This result disagreed with Ulger et al., (2018), who developed a study about evaluation of nutrition education during pregnancy and nutritional knowledge of pregnant women, and reported that less than half of the studied women were in the first trimester.

In addition, more than half of the studied women were suffering from urinary tract infection during the current pregnancy and more than half of them get the infection twice. These findings were agreed with Amiri et al., (2015), who performed a study about prevalence of urinary tract infection among pregnant women and its complications in their newborns during the birth in the hospitals of Dezful city, Iran, and found that the majority of the studied women were suffering from urinary tract infection during pregnancy had hospitalized twice. This might be because of the insufficient personal hygiene during pregnancy a well as the insufficient information about the urinary tract infection during pregnancy and its effect in both mother and baby.

Concerning the studied women medical history; the study results showed that most of the studied women didn't suffer from any diseases, while less than half of them who were suffering from diseases were suffering from hypertension. These findings disagreed with Vettore et al., (2013), who performed a study about assessment of urinary infection management during prenatal care in pregnant women attending public health care units in the city of Rio de Janeiro, Brazil, and found that anemia was more frequent in the pregnant women with urinary tract infection. This might be because both hypertension and anemia are the most common diseases among pregnant women.

Knowledge is a familiarity, awareness, or understanding of someone or something, such as facts (propositional knowledge), skills (procedural knowledge), or objects (acquaintance knowledge). Urinary tract infections UTIs are common during pregnancy; the most common causative organism is Escherichia coli. Urinary tract infections UTIs in pregnant women should be treated to prevent complications such as premature labor. Asymptomatic bacteriuria can lead to the development of cystitis or pyelonephritis. Pyelonephritis can be a life-threatening illness, with increased risk of perinatal and neonatal morbidity (Smaill, 2017). Educational guidelines help pregnant women know, understand and perform healthy self-care practices in their daily life to relieve their 
urinary tract infection symptoms during pregnancy (Hssan, 2015).

Concerning the studied women's total knowledge about urinary tract infection; the results of the present study revealed that less than three quarters of the studied women had average total knowledge, while one quarter of them had poor total knowledge, and the minority of them had good total knowledge. This low score of knowledge might be due to there were no awareness rising programs about UTI and its effect on both mother and childbirth and absence of health care provider's recommendation regarding UTI with pregnancy.

These findings agreed with Lele et al., (2016), who studied the prevalence of urinary tract infection among pregnant women attending antenatal clinic at a tertiary care centering Al Rass, Al Qassim, and found that the majority of women had average total knowledge about urinary tract infection, while less than one quarter of them had poor total knowledge, and no one had good total knowledge. Also these findings agreed with Rahimi et al., (2016), who developed study about evaluation of knowledge, attitude and behavior in the field of urinary tract infection among the pregnant women consulted in health centers Zahedan city, Iran, based on the health belief model, and found that the minority of the studied women had good total knowledge score.

As regards the studied women's total attitudes about urinary tract infection; most of the studied women had total positive attitude, while less than one fifth of them had negative attitude about urinary tract infection. These findings supported with Bhat et al., (2017), who conducted a study about knowledge and attitude regarding urinary tract infection (UTI) and its prevention during pregnancy, and denoted that the majority of the studied women had total positive attitude, while more than one fourth of them had negative attitude about urinary tract infection. Also, these findings supported with Santoso et al., (2017), who found that more than half of the studied subjects showed a total positive attitude, while the rest of them showed negative total attitude about urinary tract infection.

Regarding the correlation between the studied women's total knowledge and total attitude score; finding of the current study showed that there was a highly statistically significant relation between the total knowledge and total attitude score of the studied women. This finding was in contrast with Bhat et al., (2017), who found that there was a highly statistically significant relation between the total knowledge and total attitude score of the studied women regarding urinary tract infection during pregnancy. Also, this finding were in agreement with El Sayed (2019), who mentioned that there was a highly statistically significant positive correlation between the studied women total knowledge and total attitude regarding urinary tract infection.

\section{Conclusion}

\section{Based on the results of the present study} and research questions, the study concluded that:

Less than three quarters of the studied women had average total knowledge about urinary tract infection. Most of the studied women had positive attitude about urinary tract infection. 


\section{$\underline{\text { Knowledge and Attitudes of Pregnant Women regarding Urinary Tract Infection }}$}

There was a highly statistically significance relation between the total knowledge score of the studied women and educational level, occupation, monthly income, residence and family type.

There was highly statistically significance relation between the total attitude score of the studied women and income and family type.

The aim was achieved and the research question was answered.

\section{Recommendations}

In the light of the present study findings the following recommendations are suggested:

This study recommended

- Health educational program should be developed and implemented for pregnant women to avoid urinary tract infection.

- a periodical educational programs for the nurses working at obstetric departments is mandatory, for the purpose of rising and updating their knowledge for urinary tract infection during pregnancy..

- Designing a booklet containing all tasks for the pregnant women is mandatory, this booklet acts as a standardized protocol of preventive measures of urinary tract infection.

- Continuing in service education programs should be designed and implemented to motivate pregnant women in achieving high competent care.

\section{Recommendations for further researches:}

- Further studies should be conducted to replicate the study on a larger sample of pregnant women and obe/ gyn nurses for generalization of results.

\section{References}

Adhikari, S., \& Dhakal, R. (2015). Knowledge on urinary tract infection among primi-gravida women. International Journal of Health Sciences and Research; 5(10): PP. 202. Amiri, M., Lavasani, Z., Norouzirad, R., Najibpour, R., Mohamadpour, M., Nikpoor, A., Raeisi, M., \& Marzouni, $\mathbf{H}$. (2015).Prevalence of urinary tract Infection among pregnant women and its complications in their newborns during the birth in the hospitals of Dezful city Iran. Iran Red Crescent Med J; 17(8): e26946.

Bhat, A., Pradna, V., Prakash, A., Prema, M., \& Geeta, E. (2017). Knowledge and attitude regarding urinary tract infection (UTI) and its prevention during pregnancy. Journal of Nursing and Health Science; 6(6): PP. 53-55.

El Sayed, H. (2019). Pregnant women perception regarding urinary tract infection. Journal of Medical and Healthcare, 2(6): PP. 65-69.

Lele, U., Amjad, A., \& Shahane, V. (2016). The prevalence of urinary tract infection among pregnant women attending antenatal clinic at a tertiary care centering Al Rass, Al Qassim. International Journal Science and Research (IJSR); 5 (5): PP.23-27.

Rahimi, A., Zareban, I., \& Shahrakipour, M. (2016). Evaluation of knowledge, attitude and behavior in the field of urinary tract infection among the pregnant women consulted in health centers Zahedan city, Iran, based on the health belief model. Scientific Information Database; 12(1): PP. 114-118.

Santoso, I., Surya, R., Yasmin, A., \& Irwinda, R. (2017). The awareness of urinary tract infection management in pregnant women. 
A qualitative study. Majalah Obstetri and Ginekologi, 25, PP. 92-96.

Ulger, T., Akçalı, C., \& Yardımc, H. (2018). Evaluation of nutrition education during pregnancy and nutritional knowledge of pregnant

women.Availableat:https://www.researchgate.n et/publication/328654406_Evaluation_of_Nutri tion_Education_During_Pregnancy_and_Nutriti onal_Knowledge_of_Pregnant_Women.

Accessed on 12 August 2020.

Vettore, M., Dias, M., Vettore, M., \& Leal, M. (2013). Assessment of urinary infection management during prenatal care in pregnant women attending public health care units in the city of Rio de Janeiro, Brazil. Rev. Bras. Epidemiology; 16 (2): P.5.

Smaill, F.(2017). Asymptomatic bacteriuria in pregnancy. Best Pract Res Clin Obstet Gynaecol. Jun 2017;21(3):439-50.

Hassan, M., (2015). Effect of intervention Guidelines on self-care practices of pregnant women with urinary tract infection. Life
Science Journal 2015;12(1) http://www.lifesciencesite.com 113

Emiru, T., Beyene, G., Tsegaye, W., \& Melaku, S. (2016): Associated risk factors of urinary tract infection among pregnant women at Felege Hiwot Referral Hospital, Bahir Dar, North West Ethiopia. BMC Res Notes; 25(6): P. 292.

Ngxongo, T. (2018). Basic antenatal care approach to antenatal care serviceprovision.Availableat:https://www.intec hopen.com/books/selected-topics-in-midwiferycare/basic-antenatal-care-approach-toantenatal-care-service-provision. Acceseed on 20 March 2020.

Samanta, A. (2016). Prevalence and health seeking behavior of reproductive tract infections/sexually transmitted infections symptomatic: Indian journal of public health, January- march; 55(1): PP.38-41. 


\section{معلومات واتجاهات السيدات الحوامل تجاه عدوي المسالكك البوليه}

\section{سنية السيد عبدالفتاح ابوالخير - امينة سعد جنيد - سعاد عبالسلام رمضانـ فاطمة كمال علي}

تعد عدوى المسالك البولية من أخطر المشاكل الصحية التى تؤثر على الملايين من الأثخاص كل عام

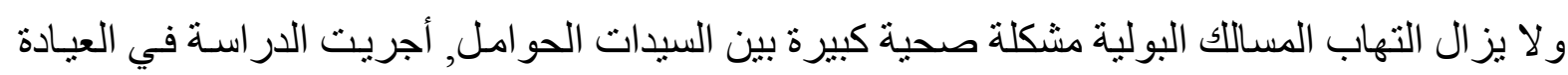

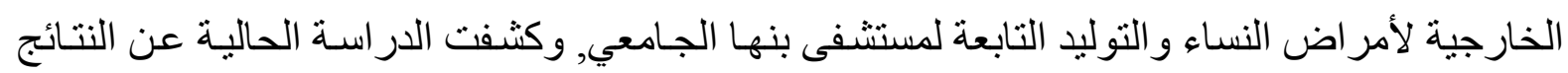

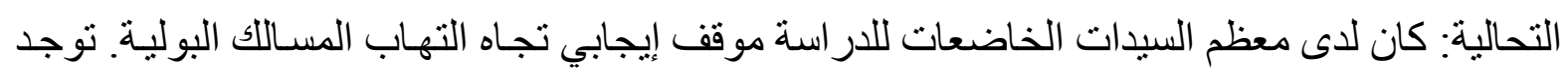
علاقة ذات دلالة إحصائية عالية بين مجموع درجات المعرفة لدى السيده المدروسـة والمستوى التعليمي لئي

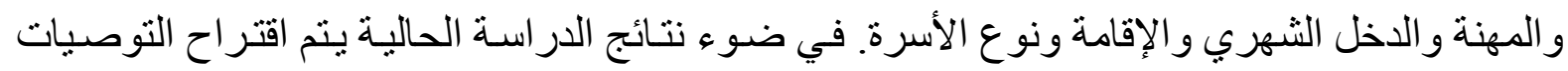
التالية: يجب وضع وتنفيذ برنامج تثقيفي مكثف للحو امل لتجنب التهابات المسالك البولية. إلز امية بر امج ونج

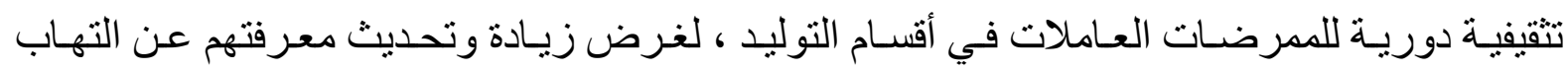
المسالك البولية أثناء الحمل. 